\title{
DEVELOPING THE STRATEGIES FOR IMPLEMENTATION OF COLLABORATIVE ALLIANCE IN THE EXTRACTIVE FIELD
}

\author{
Yuliia Halynska \\ Department of Management \\ Sumy State University \\ 2 Rimskogo-Korsakova str., Sumy, Ukraine, 40030 \\ galinskaja.julia@gmail.com
}

\begin{abstract}
We developed the matrix of strategies for implementing the mechanism of collaborative alliances between the state and the extractive enterprises for the creation of social responsibility in the natural resource extraction. The matrix of strategies consists of blocks and is divided by levels of willingness to cooperate within the collaborative alliances in the field of natural resources.

The synergy effect of common strategies of alliances increases with the balance of these strategies, which reflects the directions of its activities. Some areas of activity are effectively implemented when the functional and resource strategies are coordinated and adapted to each other and to the strategies of innovation and basic level. The coordination between the strategies minimizes risks, engages collaborative partners, creates innovative products and services, and implements socially-oriented policies in the mining regions.

The result has showed that the potential for implementing the proposed strategies is very high, but it is necessary to specify the risks when coordinating the interests of all alliance participants for each mining region, as the formation of a "block of strategies" depends on the risks identified in a specific region.
\end{abstract}

Keywords: strategic management, strategic thinking, block of strategies, nature management.

\section{Introduction}

Accelerating changes in the environment, emergence of new inquiries and changing the position of the consumer and the manufacturer, increased competition for resources, business internationalization, emergence of new, often absolutely unexpected opportunities for business, development of information networks, which make it possible to lightly disseminate and obtain information, broad availability of modern technologies, changing the role of human resources, as well as a number of other factors have led to a sharp increase in the value of strategic management. The scope of application of the strategic management changed as well. If we have previously considered the strategies at the firm level and the firm's interaction with the environment, now the strategic management is increasingly applied at the state and interstate levels when implementing the goals of the collaborative alliances and implementing the regional development programs. The very management concept is constantly evolving as well. Good or, to be more precise, effective management is a management that seeks not to be correct, but to do impossible thing [1]. Management deals not with logic but with interests, therefore, it is always in a state of search, and therefore, the management theory is constantly evolving, which reflects the most successful examples of managerial activity, the best (most effective) management practice [2].

\section{Analysis of the literature data and the formulation of the problem}

The term "strategic management" was introduced in the use from the late $60 \mathrm{~s}$ and $70 \mathrm{~s}$ to mark the difference between the current management at the production level and the management carried out at the highest level. The need to fix such a difference was primarily due to changes in the business conditions. The development of the strategic management ideas has been reflected in the works of such authors [3-6]. The leading idea that reflects the essence of transition from the operational management to the strategic one was the idea of the need to shift the focus of attention of senior management to the environment, in order to properly and timely respond to the changes occurring in it. 
It is possible to specify several constructive definitions that have been proposed by the authoritative developers of the strategic management theory. Some authors regarded it as "the process of identifying and (establishing) the relationship of the organization with its environment, consisting in implementation of the chosen goals and in attempts to achieve the desired state of relationship with the environment through the allocation of resources, which enables the organization and its subdivisions to operate effectively and efficiently" [7]. The "strategic management is the management process aimed at implementing the organization's mission through the management of the organization's interaction with its environment" [8-11]. Pearce and Robinson define the strategic management "as a set of decisions and actions on the formulation and implementation of strategies developed in order to achieve the organization's goal" [12].

There is still a number of definitions that emphasize certain aspects and peculiarities of the strategic management or its distinction from the "ordinary" management. However, when it comes to the strategic management, it is important to firstly understand that it is a management component, which has its core in terms of the senior management theoretical work aimed at finding the solutions that will help the organization survive in a dynamically changing environment in a context of fierce competition, wherein each participant in the competition wants to do everything possible to win [1]. The management strategy in the creation of collaborative alliances and partnerships deserves particular attention. It is so, because it is possible to develop an effective strategic management approach for the business entities and manage them effectively in the context of the collaborative allocation of resources, finance and risks.

The international business literature has already recognized a number of positive results for the companies actively engaged in the strategic alliances. The main positive aspects are: higher return on investment, better return on investment and higher success rates compared to the integration through mergers and acquisitions [13]. However, not all the business managers choose the collaboration strategy, especially of those enterprises where they are practically monopolists. This is confirmed by the fact that there was little understanding among the business managers about the processes of formation and development of inter-corporate relations and factors that determine success in the strategic alliances [14].

\section{The aim and the tasks of the research}

The aim of the work is to develop strategies for implementing collaborative alliances in the extractive field.

To achieve this goal, the following tasks were set:

1. Identify the main risks in the creation and functioning of collaborative alliances (power - society - enterprise).

2. To rank the risks identified by the degree of significance for the add-on of Fuzzy Logic.

3. To develop a matrix of strategies, taking into account the specifics of the sphere of natural resource in Ukraine in the conditions of a transitive economy.

4. Determine the average of the identified risks and integrate them into the developed matrix of strategies.

\section{Methods of research}

In this study, an empirical method was used, an expert assessment method for identifying and ranking possible risks in the operation of collaborative alliances in the use of natural resources, the Fuzzy Logic method, and a scenario approach when combining different policy scenarios.

\section{Main material}

In accordance with the Decree of the President of Ukraine "On the Strategy of Sustainable Development "Ukraine-2020" [6], which consists of three vectors of movement: sustainable development of the country; security of the state, business and citizens; responsibility and social justice, we offered a mechanism for implementing the collaborative alliances in the nature management through the development of a "block of strategies" in this article. The main prerequisite is a new 
social contract between the civil society, government and business, where each party has its own area of responsibility.

In our opinion, the block of strategies shall mean the minimum-necessary set of strategies of different values and different intensity of implementation.

According to the definition of "block of strategies", coordination of strategies of different types is necessary. A collaborative alliance can achieve common goals, provided that the strategies are balanced, the interaction of particular types in the "strategic set" is substantiated, which contributes to their mutual reinforcement, that is, helps to achieve the synergy effect. The synergy effect of common strategies of alliances increases with the balance of these strategies, which reflects the directions of its activities. Some areas of activity are effectively implemented when the functional and resource strategies are coordinated and adapted to each other and to the strategies of innovation and basic level. The coordination between the strategies minimizes risks, engages collaborative partners, creates innovative products and services, and implements socially-oriented policies in the mining regions.

One of the main goals of strategic management in the context of collaboration is to ensure a rational allocation of resources among all the participants in the collaborative alliance and to introduce social responsibility towards the community on the territory of the natural resource extraction.

The strategic goals, in order to be achieved in the future, require decisions on the resources consumption even today. The future is always uncertain, so the resources consumption will always be accompanied by one or another level of risk. It is impossible to get rid of risk completely; the risk minimization usually requires extra costs and may be uneconomic. When developing the strategies, it is necessary to justify the possible and acceptable levels of risk, which shall be incurred by the management board when using the resources with the maximum possible return.

Taking into account the above, the article offers to implement a minimum-necessary block of strategies for the implementation of a collaborative alliance between the state and the extractive enterprises on the establishment of social responsibility in the mining regions. This block of strategies is presented as a matrix.

The strategy matrix consists of three levels: "Low", "Medium", "High". At level consists of four strategies that characterize the selected block of strategies. The first level includes the basic strategies, the second - resources, the third - functional, the fourth - innovative. We offer to implement a "block of strategies" that meets the risk level for a particular collaborative alliance.

The implementation of the "block of strategies" is due to the fact that:

- the implementation of one of these strategies is all the same prompts the structural and functional changes in the alliances;

- the level of strategies is determined by the identified and ranked risks when creating a specific collaborative alliance;

- the identified risks relate to various managerial sub-divisions, so all the problems cannot be covered by one strategy.

Classification of strategies

According to the proposed matrix of strategies, each block should consist of the following types of strategies such as:

- basic (portfolio, business strategies aimed at creating and implementing new products, technologies and services);

- functional (scientific and technical, production, marketing, service);

- resource (financial, labor, informational, material and technical);

- innovative (technologies, structures, methods, management systems).

The strategies are also characterized by the degree of readiness to implement the "Low", "Medium", "High" collaborative mechanisms, that is, it indicates the degree of openness of the nature management enterprises to the readiness to reconcile their interests with the external environment in the natural resource extraction.

The block of basic strategies includes:

- planning strategy. This strategy gives the real opportunities to get into the market where the manufacturers, using the planning strategy, may sell their products without obstacles; 
- implementation strategy. This strategy implies the manufacturer's desire to stick to the already conquered market with medium or even outdated products in innovative terms. This strategy can be applied when a producer-leader emerges from the competition in this area of innovation;

- development strategy. The advanced scientific content strategy. It is characterized by the desire to have a high level of scientific content higher than the average level in the industry. This strategy applies when the time when a new product appears on the market is important, when it is important to outsource other companies in lowering prices and costs.

The block of resource strategies includes:

- accumulation strategy. This strategy involves significant savings on research and development, in some cases, and on other costs associated with the conquest and maintenance of leading positions in the extractive industry in other cases. The enterprises that use this strategy usually use every opportunity to take advantage of the experience and achievements of the enterprises that are leading in this innovative area, which enables to purposefully reduce expenditures for the production development;

- strategy for maintaining technological positions. It is suitable for the enterprises that hold strong competitive positions, but for some reason, experience strong and unexpected pressure on the part of competitors and cannot invest the necessary funds in production upgrading at some stages of development. Such a strategy cannot be successful in the long run;

- strategy for implementing new technologies. The basis of this strategy is the overwhelming advantages of the market, the orientation on advancement in the innovation activities of competitors and an increase in this gap.

The block of functional strategies includes:

- motivational strategy. This strategy involves the search for motivational managerial decisions that do not require significant research and development costs, but with which the company will be successful in the market for a long time;

- simulation strategy. The simulation strategy is used by the collaborative alliances with weak market positions that are not pioneers in the release of innovations. In this case, the main consumer properties of innovations released to the market by other enterprises are copied. The simulation strategy is based on focusing the company's efforts and finances on production capital investments, their rapid development, and effective marketing. It minimizes the investment risk, technological risk, reduces commercial and financial risk;

- stimulating strategy. It involves a transition to the higher stages of technological development, bypassing the lower ones. It is closely related to the simulation strategies.

The block of innovative strategies includes:

- strategy of retaining competitive advantages. The main feature of this strategy is to find the optimal "cost - result" ratio in the collaborative process. The main purpose of this strategy is the timely reaction of the enterprise to the actions of competitors and the behavior of consumers;

- management organization strategy. This strategy is related to certain changes in the organization of enterprise management and the introduction of innovative management methods in the alliance system;

- strategy of increasing competitive advantages. It is usually used by powerful and large enterprises. The complexity of this strategy in terms of management lies in the fact that it is necessary to continually hold on to the second place in the group of applicants for leadership, to pursue an effective innovation policy.

In order to determine the required block of strategies for a collaborative alliance, it is necessary to determine the dependence function of the identified risks. Table 1 offers a dependence function for the 10 risks identified in creating the collaborative alliances between the state and the extractive enterprises in the natural resource extraction.

Fig. 1 presents graphically the membership function proposed in Table $\mathbf{1}$.

In accordance with the classification proposed in Table $\mathbf{1}$ of the studied variables, based on the previously obtained values, we obtain a summary table of analysis of the studied variables. 
Table 1

Membership function and classification of the current factor value

\begin{tabular}{ccc}
\hline Value interval V & Classification of factor level V & Confidence degree \\
\hline $0.086 \leq \mathrm{V} \leq 0.129$ & $\mathrm{~V}_{1}$ & 1 \\
$0.129<\mathrm{V}<0.217$ & $\mathrm{~V}_{1}$ & $\propto_{1}=11.363(0.217-\mathrm{V})$ \\
$0.217 \leq \mathrm{V} \leq 0.289$ & $\mathrm{~V}_{2}$ & $1-\propto_{1}=\propto_{2}$ \\
$0.289<\mathrm{V}<0.344$ & $\mathrm{~V}_{2}$ & 1 \\
$0.344 \leq \mathrm{V} \leq 0.404$ & $\mathrm{~V}_{2}$ & $\propto_{2}=18.182(0.344-\mathrm{V})$ \\
$0.404<\mathrm{V}<0.468$ & $\mathrm{~V}_{3}$ & $1-\propto_{2}=\propto_{3}$ \\
$0.468 \leq \mathrm{V} \leq 0.558$ & $\mathrm{~V}_{3}$ & 1 \\
$0.558<\mathrm{V}<0.673$ & $\mathrm{~V}_{3}$ & $\propto_{3}=15.625(0.468-\mathrm{V})$ \\
$0.673 \leq \mathrm{V} \leq 0.737$ & $\mathrm{~V}_{4}$ & $1-\propto_{3}=\propto_{4}$ \\
& $\mathrm{~V}_{4}$ & 1 \\
& $\mathrm{~V}_{4}$ & $\propto_{4}=8.695(0.673-\mathrm{V})$ \\
& $\mathrm{V}_{5}$ & $1-\propto_{4}=\propto_{5}$
\end{tabular}

Table 2

Classification of the studied factors

\begin{tabular}{lcccc}
\hline No. Name of variable & \multicolumn{3}{c}{ Expected value } \\
important & $\begin{array}{c}\text { Permis- } \\
\text { sible }\end{array}$ & $\begin{array}{c}\text { Has some } \\
\text { importance }\end{array}$ & Important & $\begin{array}{c}\text { Very } \\
\text { important }\end{array}$ \\
\hline
\end{tabular}

1 Decrease in the resource price

0.395

2 the social component in the contracts

0.561

3 Increase in the amount of 0.97 0.561 rent payments

0.479

4 Increase in the costs of companies for extraction of a natural resource unit

Development of shadow schemes for determining the rental income

6 Increase in the resource price

7 Opportunistic behavior of the parties upon the interests negotiation

State control over the key sectors of

8 economy, which form a significant rental income

9 Resource depletion in the region

10 Necessary changes in the legislative framework

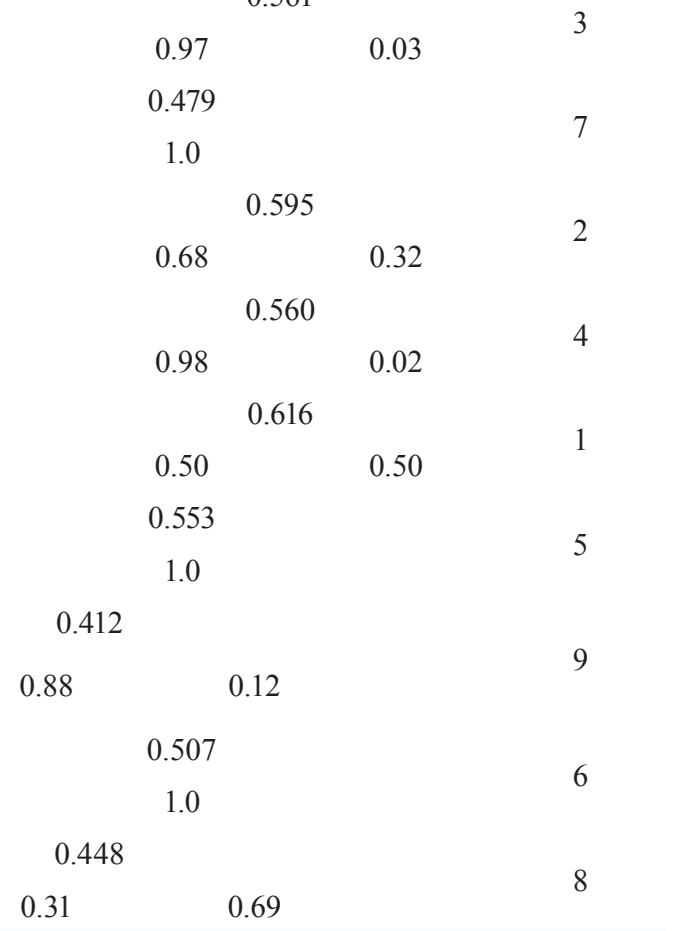




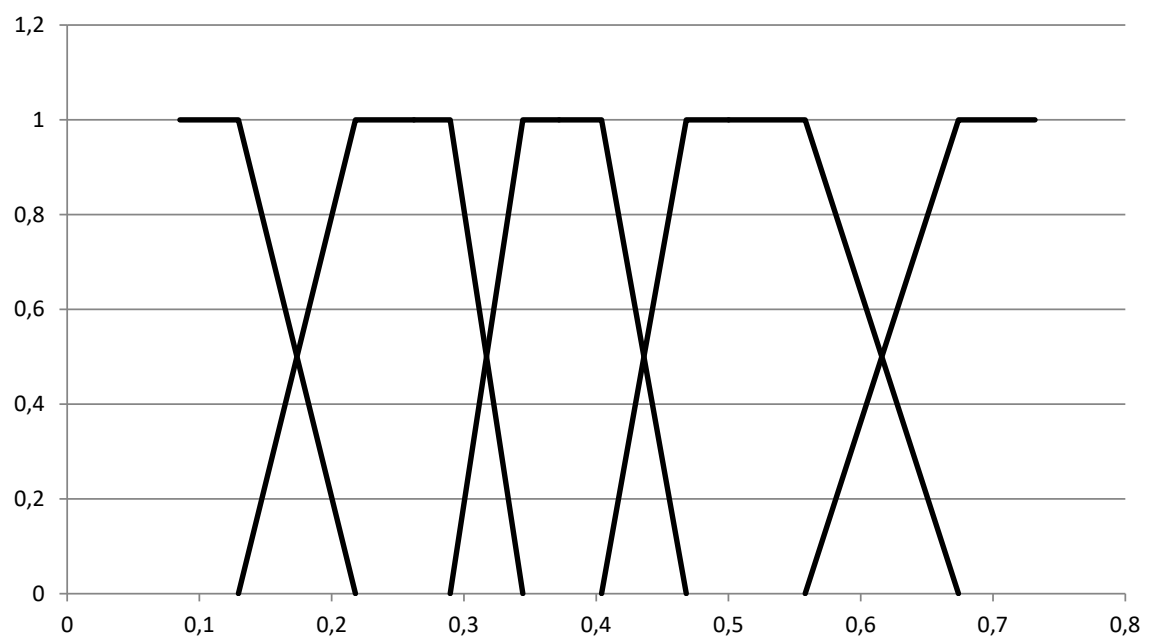

Fig. 1. Membership function

Each block of strategy should consist of "basic", "resource", "functional" and "innovative" strategies. The strategy is determined by determining the significance level of the identified risks when forming a specific collaborative alliance.

- At the first stage, using the expert method, the identified risks are ranked according to the significance and the membership function and the classification of current factor value are determined.

- At the second stage, the risk significance level is identified, which can be identified as "unimportant", "admissible", "significant", "important", "very important" when forming the collaborative alliances.

- At the third stage, the interdependence between the risks is determined in the formation of a collaborative alliance between the state and the extractive enterprises.

- The revealed factor values relate to the strategy matrix. In this case, the most of the factors fall into the High block. This means that this collaborative alliance is ready for changes in the field of nature management and the adoption of innovative management decisions (Fig. 2).

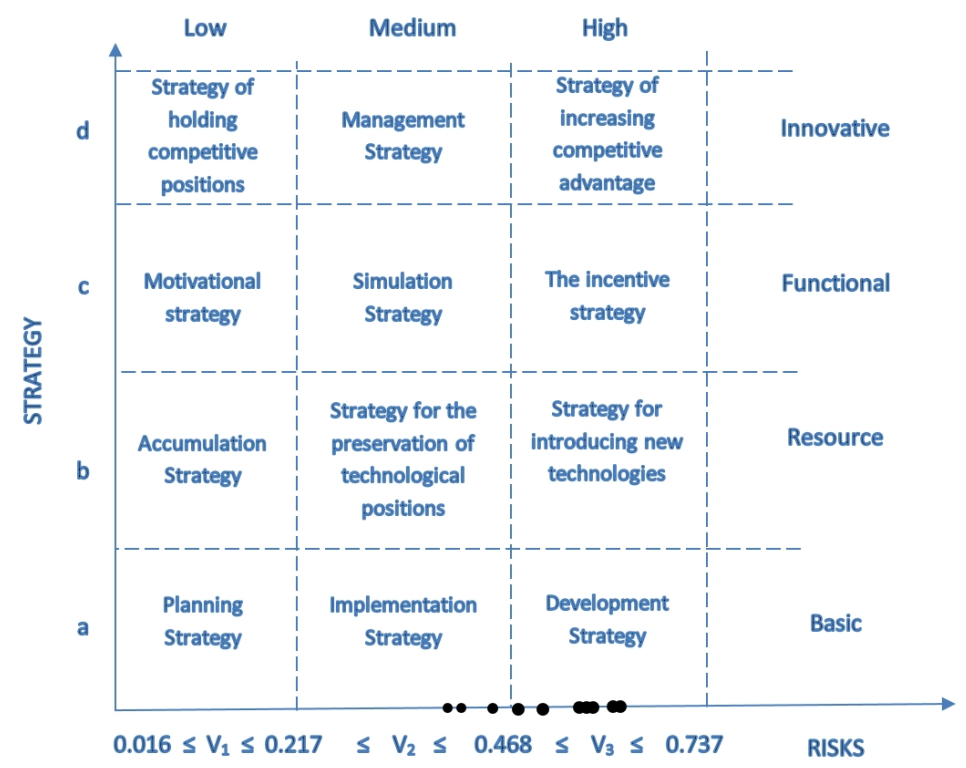

Fig. 2. Scheme of changes in the field of nature management and the adoption of innovative management decisions

\section{Discussion of results}

The matrix of strategies is a logical continuation of the research, according to which we consider the need to create collaborative alliances in the system (state-society-enterprises) in the 
extractive field. In the process of the study, risks were identified that could be insurmountable and a barrier in the coordination of the interests of all parties.

Therefore, there was a need to develop a mechanism for implementation of strategies that determines the level of readiness of systems (state-society-enterprise) to the creation and functioning of collaborative alliances in environmental management.

The main advantage of this method is an individual approach to each system, taking into account the emergence of personal risks in a particular territory in the extraction of natural resources

\section{Conclusion}

1. A study was conducted to identify risks in the creation and operation of collaborative alliances in the natural resource sector. Risk identification will make it possible to identify threats that the collaboration system (state-society-enterprise) may encounter when creating a collaborative mechanism, which in turn will negatively affect the socio-economic development of the region.

2. Using the Fuzzy Logic method, we identified the most significant risks from the entire set of risks, taking into account the integral indicator of the stability of collaborative alliances. We have applied this ranking in determining the block of strategies for a particular collaboration system.

3. We developed the matrix of strategies for implementing the mechanism of collaborative alliances between the state and the extractive enterprises for the creation of social responsibility in the natural resource extraction. The matrix of strategies consists of blocks and is divided by levels of willingness to cooperate within the collaborative alliances in the field of natural resources.

Strategies are combined in such a way as to correspond to a specific level of the block of readiness for collaboration.

The synergy effect of common strategies of alliances increases with the balance of these strategies, which reflects the directions of its activities. Some areas of activity are effectively implemented when the functional and resource strategies are coordinated and adapted to each other and to the strategies of innovation and basic level. The coordination between the strategies minimizes risks, engages collaborative partners, creates innovative products and services, and implements socially-oriented policies in the mining regions.

4. Using the Fuzzy Logic method, we determined the average of the identified risks in our study. In accordance with the meaning, we integrated the risks into the strategy matrix. The result has showed that the potential for implementing the proposed strategies is very high, but it is necessary to specify the risks when coordinating the interests of all alliance participants for each mining region, as the formation of a "block of strategies" depends on the risks identified in a specific region.

The strategies proposed in the interest collaboration solve the following issues:

1) provision of a rational allocation of resources among all the participants in the collaborative alliance;

2) introduction of social responsibility in relation to the community on the territory of the natural resource extraction;

3) definition of the main risks during the natural resource extraction for the current period;

4) definition of perspective needs of enterprises and communities in the resources of all necessary kinds;

5) calculation of permissible resource constraints and formation of progressive norms of resources consumption of various types;

6) definition of "areas of strategic resources", possibilities of their use by balancing volumes and composition, delivery terms with the consumption dynamics;

7) development of measures for rational transportation, storage and use;

8) introduction of new modern environmental technologies in the natural resource extraction;

9) coordination of interests of local communities, extractive enterprises and the state in the nature management. 


\section{References}

[1] Vikhanskiy, O. S., Naumov, A. I. "Management” Course Practicum. Moscow: Gardarika, 1998.

[2] Vikhanskiy, O. S. Strategic Management. Moscow: Publishing House of the Moscow State University, 252 .

[3] Beloshapka, V. A., Zgoriy, G. V. (1998). Strategic Management: Principles and International Practice. Kyiv: Absolut - V, 352.

[4] Klishyna, Yu. N. (1991). The Use of Correspondence Analysis in the Treatment of Non-Numerical Information. Sociology, 4M (2), 105-118.

[5] Lei, D. (1993). Offensive and defensive uses of alliances. Long Range Planning, 26 (4), 32-41. doi: 10.1016/0024-6301(93)90055-k

[6] Decree of the President of Ukraine "On the Strategy of Sustainable Development "Ukraine-2020". (2015), 5/2015

[7] Sim, A., Ali, Y. (1998). Performance of international joint ventures from developing and developed countries: An empirical study in a developing country context. Journal of World Business, 33 (4), 357-377. doi: 10.1016/s1090-9516(99)80080-7

[8] Ansoff, I. (1999). New Corporate Strategy. Saint Petersburg: Piter Publishing House, 416.

[9] Ansoff, I. (1989). Strategic Management. Moscow: Ekonomika, 519. cases, 445 .

[10] Higgins, J., M., Vincze, J. W. (1993). Strategic management and organizational policy: text and

[11] Ortina, H. V. (2010). Methodological Concepts for Defining the Enterprise Strategic Management. Efektyvna ekonomika, 4. Available at: http://www.economy.nayka.com.ua/?op=1\&z=197

[12] Pearce, J. A., Robinson, R. B. (2011). Strategic Management: Formulation, Implementation, and Control, 992.

[13] O' Farrell, P. N., Wood, P. A. (1999). Formation of Strategic Alliances in Business Services: Towards a New Client-Oriented Conceptual Framework. The Service Industries Journal, 19 (1), 133-151. doi: 10.1080/02642069900000008

[14] Mintzberg, H. (1987). The Strategy Concept I: Five Ps for Strategy. California Management Review, 30 (1), 11-24. doi: 10.2307/41165263 